\title{
Nutrient bioavailability of white lupine in complete feed for non-human primates
}

\author{
Nikolay Gaponov ${ }^{1,2, *}$, and Olga Loretts $^{3}$ \\ ${ }^{1}$ FSBSI "Research Institute of Medical Primatology", Mira Str., 177, 354376, Sochi, Krasnodar Krai, \\ Russia. \\ ${ }^{2}$ All-Russian Lupine Scientific Research Institute - Branch of the FSBS Institution "Federal Williams \\ Research Center of Forage Production and Agroecology", Berezovaya Str., 2, 241524, village \\ Michurinsky, Bryansk region, Russia. \\ ${ }^{3}$ Ural State Agrarian University, 620075 Karl Liebknecht str., 42, Yekaterinburg, Russia
}

\begin{abstract}
The article is devoted to the current world problem of vegetable protein deficiency, the solution of which can be white lupine. Particular attention is paid to assessing the bioavailability of nutrients from white lupine (Lupinus albus) in the body of non-human primates M. Mulatta. Because primates are phylogenetically closer to humans than other laboratory animals, which is very convenient for modeling and studying the digestibility of nutrients in diets. The purpose of the article is to study the digestibility of nutrients in lupine in the structure of complete feed and its effect on the biochemical parameters of the blood. As a result of the research, it was found that the inclusion of white lupine in the structure of the diet allows to improve the bioavailability of nutrients of complete feed, when included in the structure of the diet of white lupine in an amount of $10 \%$, it made it possible to improve the digestibility of crude protein in relation to the control group by $5.5 \%$, crude fat by $0.99 \%$, crude fiber by $1.84 \%$, BEV by $7.99 \%$, crude ash by $4.67 \%$, calcium $(\mathrm{Ca})$ and phosphorus (P) by $6.99 \%$, and $1.02 \%$. With the inclusion of $20 \%$ white lupine in the structure of the diet, it made it possible to improve the digestibility of crude protein in relation to the control group by $9.28 \%$, crude fat by $6.5 \%$, crude fiber by $5.98 \%$, BEV by $2,78 \%$, crude ash by $11.28 \%$, and absorption of calcium (Ca) and phosphorus (P) by $9.93 \%$ and $8.68 \%$. At the same time, the results of hematological analyzes generally indicate the safety of consuming white lupine for 35 days.
\end{abstract}

\section{Introduction}

The content of nutrients in diets determined by chemical analysis can be misleading in terms of their nutritional value. In addition to the amount, it is important whether the nutrient is in a form that can be used in metabolism; that is, whether the nutrient is bioavailable $[12 ; 25$; 30]. Many factors affect the bioavailability of nutrients. There are many examples of how the

\footnotetext{
* Corresponding author: nv.1000@bk.ru
} 
composition of lupin (Lupinus albus) nutrients and their bioavailability are affected by processing and storage $[1 ; 6 ; 12]$. In addition to the qualitative characteristics of lupin, different animal species show differences in the bioavailability of certain substances contained in lupin. Age, gender, physiological state and other factors affect the ability to absorb a certain nutrient $[17 ; 27]$. The bioavailability of carbohydrates, proteins, fats, vitamins and minerals can be increased or decreased, since all nutrients are reactive and are usually present in various amounts in diets. Questions often arise whether it is necessary to have an accurate quantitative assessment of the bioavailability of nutrients, or whether an assessment of the relative bioavailability by the biochemical composition of lupin nutrients will be sufficient. The answer is unambiguous, an accurate quantitative measure of the bioavailability of lupin nutrients is required to calculate the satisfaction of the needs of the human and animal body in macro-micronutrients. In this case, it is important to have sufficiently reliable quantitative data to balance the nutrients necessary for daily consumption and to compensate for their endogenous losses $[11 ; 23 ; 25]$.

Various animal models are used to determine the digestibility of nutrients by the in vivo method. Laboratory tests with the participation of animals are an essential stage of procedures performed to assess the effectiveness of the bioavailability of nutrients in diets and food additives. As a rule, rodents (mice, rats, guinea pigs) or agricultural animals (pigs, birds, etc.) act as laboratory test subjects $[15 ; 23]$. The main problem that should be considered initially when using animal models to assess the bioavailability of nutrients is that how accurately these different model systems reflect the bioavailability of nutrients in the human body. For example, conventional experimental animal models, such as rats and mice, cannot be used to assess the bioavailability of beta-carotene, because the mechanism of absorption in rodents for this nutrient is very different from the mechanism in humans $[25 ; 27 ; 30]$. Unlike rodents, non-human primates, a suitable experimental model, at least simulate the intestinal absorption of carotenoid and other nutrients. That is why in recent years, non-human primates are among the most used laboratory animals. Because phylogenetically primates are closer to humans than other laboratory animals, and therefore they are very convenient for modeling and studying the digestibility of nutrients in diets $[5 ; 13 ; 16]$.

The greatest relevance of using non-human primates such as M. mulatta as experimental models is acquired when studying the bioconversion of white lupine [25; 30]. Since in our country today, lupin is used as a fodder and break crop. There is a certain problem with the introduction of this crop into food products due to the weak knowledge of lupin metabolism in the human body. Therefore, lupin is not present in the list of food products both in SanPiN 2.3.2.1078-03 and in the adopted technical regulations [10].

In this regard, the purpose of the study was to study the bioavailability of nutrients of white lupine (Lupinus albus) in complete feeds of non-human primates of the species (Macaca mulatta) and the effect on blood biochemical parameters.

\section{Materials and methods}

In the experiments, 12 male rhesus macaques (M. mulatta, nursery of the FSBRI "Research Institute of MP") aged from 7 to 15 years were used. Primates of 4 heads by the method of pairs of analogues were divided into three groups, a control group and two experimental ones, considering gender and age. The groups differed in the feeding diet [14; 7]. The animals were kept in individual cages. The experiment period was 35 days.

Animal experiments were performed in accordance with the requirements of the guidelines for the maintenance of laboratory animals [298], the Helsinki Declaration (2000) and the EU Directive 2010/63/EU. The study was approved by the Bioethical Commission 


\section{of the FSBSI "SRI MP".}

The feeding of rhesus macaques (M. mulatta) was carried out with comlete feeds with a nutritional value calculated according to feeding standards. The calculated concentrations of nutrients were based on our own and foreign studies on non-human primates [4; 14]. Carrying out balance experiments allowed to determine the digestibility of nutrients, the accessibility of feed. During the research, the following indicators were considered: - zootechnical safety, live weight in total for the experience, feed costs; - physiological and biochemical chemical composition of feed, fecal nitrogen, exchange energy $[2 ; 8]$.

The scheme of the experiment is presented in Table 1.

Table 1. Experiment scheme.

\begin{tabular}{|c|c|c|}
\hline Groups & $\begin{array}{c}\text { Amount of } \\
\text { individuals }\end{array}$ & Feeding conditions \\
\hline $\begin{array}{c}1 \\
\text { Control }\end{array}$ & 4 & Complete feed (CF) \\
\hline $\begin{array}{c}2 \\
\text { Experimental }\end{array}$ & 4 & CF - content of white lupine is $10 \%$. \\
\hline $\begin{array}{c}3 \\
\text { Experimental }\end{array}$ & 4 & CF - content of white lupine is $20 \%$. \\
\hline
\end{tabular}

Note: $\mathrm{CF}$ is a complete feed

The control group received a complete balanced feed.

Primates of the 2-experimental group, with complete feed, consumed native white lupin (Lupinus albus) in the amount of $10 \%$.

In primates of the 3-experimental group, native white lupin (Lupinus albus) was present in the structure of complete feed in the amount of $20 \%$.

The bioavailability of nutrients, growth rate and hematological parameters of male rhesus macaques were studied in a physiological experiment, which was divided into two periods.

At the first stage, the animals were prepared for the conditions of cage maintenance for 5 days. Cage batteries were placed evenly along the entire length of the vivarium. Technological passages were left between the cage batteries and in the ends of the vivarium. The room was disinfected. After disinfection before setting M. mulatta, the room was sanitized. In the experimental complete feeds, part of the vegetable and animal feed was replaced with native Lupinus albus. The feeding schedule of primates in the experimental period was the same as in the control group. At the second stage, a thorough accounting of the consumed feed and excrement was carried out for 5 days. Feces were collected daily at the same time (morning and evening), weighed and pounded with a pestle. At each collection, $50 \%$ of the homogenized mass was taken for analysis. The collected portions were stored in the refrigerator. After the end of the accounting period, the initial moisture was determined in the collected feces samples by drying at $60-70{ }^{\circ} \mathrm{C}$ to constant mass. The obtained data were used to calculate the total cost of feed and protein in total for the experiment.

The inorganic part of the biochemical composition of the complete feed and feces was determined using an X-ray fluorescence wave dispersion spectrometer "Spectroscan max GVM". Method of measuring the mass fraction of $\mathrm{Mg}, \mathrm{Al}, \mathrm{Si}, \mathrm{Zn}, \mathrm{P}, \mathrm{S}, \mathrm{Cl}, \mathrm{K}, \mathrm{Ca}, \mathrm{Ba}, \mathrm{Ti}, \mathrm{Cr}$, $\mathrm{Mn}, \mathrm{Fe}, \mathrm{Ni}, \mathrm{Br}, \mathrm{Rb}, \mathrm{Sr}$ in powder samples of plant materials - by X-ray fluorescence method using X-ray devices for spectral analysis SPECTROSCAN MAX (M-049-RM/12, Russia) FR.1.31.2014.17343. The methodology is certified in the FSUE "VNIIM n.a. D.I. Mendeleev". The remaining indicators were determined using the FOSS NIRS DS2500F spectral feed analyzer (USA).

The state of health and changes in the homeostasis of the primate organism as a result of 
the inclusion of white lupin in the diets were monitored by the results of biochemical blood serum tests. The material for the study was venous blood and blood serum. Blood samples (2.5-3.0 $\mathrm{ml})$ were taken from the ulnar or femoral vein on an empty stomach before the use of chlorella and 35 days after the end of the experiment. Whole blood was stabilized with a heparin solution. Blood serum was obtained from venous blood without anticoagulants in a centrifuge glass tube, which was maintained at a temperature of $15-20^{\circ} \mathrm{C}$ until a clot forms. Decanting and centrifugation was performed with a thin glass rod (10 minutes at 1000-1500 g). The biochemical analysis (the content of total protein, glucose, total bilirubin, calcium, phosphorus) was performed with blood serum without hemolysis for 2-3 hours after receiving it using commercial kits from High Technology Inc (USA) on a semi-automatic BioChem SA analyzer (USA) in accordance with the manufacturer's instructions.

The obtained results were processed statistically in the GraphPad Prizm 8.0 program (USA) and expressed in the form of arithmetic averages and their standard errors. The statistical significance of the differences was determined using a one-factor variance analysis with subsequent a posteriori corrections for multiple comparisons using the Tukey and Sidak method. The accepted level of statistical significance is $\mathrm{p}<0.05$ [9].

\section{Results of the study and their discussion}

The first control group received a complete balanced feed for 35 days, in which $34.10 \%$ was wheat. The share of soybean cake, sunflower, corn and corn gluten in the structure of complete feed accounted for $10.00 \%$ each. The sources of animal feed were fish flour in the amount of $6.00 \%$, egg powder $-2.00 \%$ and dry milk $4.00 \%$. The diet of the control group was balanced in terms of energy by the introduction of sunflower oil, the an amount of $0.3 \%$ and sugar - $6 \%$. The lack of calcium and phosphorus macronutrients is balanced by the introduction of tricalcium phosphate in the amount of $3 \%$ and a premix $-3.6 \%$.

The feeding ration of the 2 nd experimental group for a set of feeds was identical with the control one. Nevertheless, the studied legume crop white lupin in the amount of $10 \%$ was added to the structure of the diet of this group. As a result, high-protein feed of vegetable origin, soybean meal and sunflower meal, were replaced with lupin by 50\%. The diet structure for the remaining feeds and additives was identical to the control group.

In the 3rd experimental group, high-protein feeds, both of vegetable and animal origin, were replaced with white lupin. As a result, white lupin was $20 \%$ in the structure, which replaced vegetable feed, soybean cake by $50 \%$, sunflower cake by $50 \%$, corn by $50 \%$ and wheat by $0.3 \%$. Animal feed: fish meal and milk powder - by $50 \%$. Since as a result of the lupin inclusion, the level of metabolic energy of the diet began to correspond to the norm, the content of vegetable oil in the diet decreased by $1.2 \%$. For the rest of the component composition, the experimental diet corresponded to the control one.

The daily accounting of the feed eaten by animals and the analysis of their chemical composition made it possible to determine the amount of nutrients consumed per day. The accounting of the feces and its chemical composition allowed to determine the amount of digested nutrients and establish the digestibility coefficients.

The analysis of the data in Table 2 indicates that the best results in the digestibility of normalized organic substances were observed in primates of the experimental groups. Thus, the digestibility of raw protein in the 2-experimental group, where white lupine was used as the test feed, the protein digestibility coefficient, in relation to the control group, was higher by $5.5 \%$. In the 3-experimental group, where a part of high-protein feeds, both of animal and vegetable origin, was replaced with white lupin in the structure of the feeding diet, protein was absorbed $9.28 \%$ more efficiently. 
Table 2. Digestibility of feed nutrients $\%,(X \pm S x)$

\begin{tabular}{|l|c|c|c|}
\hline \multirow{2}{*}{\multicolumn{1}{c|}{ Indicators }} & \multicolumn{3}{c|}{ Group } \\
\cline { 2 - 4 } & 1-control & 2-experiment & 3-experiment \\
\hline Protein & $49.34 \pm 0.26$ & $54.84 \pm 0.53^{* *}$ & $58.62 \pm 0.17^{* *}$ \\
\hline Fat & $39.10 \pm 0.28$ & $40.09 \pm 0.03$ & $45.60 \pm 0.08^{*}$ \\
\hline Fiber & $19.18 \pm 0.31$ & $21.02 \pm 0.18^{*}$ & $25.16 \pm 0.28^{*}$ \\
\hline NFES & $70.12 \pm 1.12$ & $78.11 \pm 2.03$ & $72.90 \pm 2.03$ \\
\hline Ash & $39.23 \pm 0.30$ & $43.90 \pm 0.29^{*}$ & $50.51 \pm 0.37^{* *}$ \\
\hline Calcium (Ca) & $40.17 \pm 1.94$ & $47.16 \pm 1.58^{*}$ & $50.10 \pm 1.96$ \\
\hline Phosphorus (P) & $49.19 \pm 0.03$ & $50.21 \pm 0.37$ & $57.87 \pm 0.66^{*}$ \\
\hline
\end{tabular}

Note: The data was obtained by averaging 4 measurements for each animal and the average value for the group $(\mathrm{n}=4)$.

$*$ - $\mathrm{p}<0.05, *-\mathrm{p}<0.01, * *$ compared with the control group. The data is given in the form of an average value and a standard error.

NFES $* * *$ nitrogen-free extractive substances

The digestibility of raw fat was the highest in the 3-experimental group, compared to the control group by $6.5 \%$. In the primates of the 2-experimental group, the coefficient of digestibility was higher by $0.99 \%$ in relation to the control.

There was a positive dynamic in the digestibility of crude fiber in experimental groups 2 and 3 by $1.84 \%$ and $5.98 \%$.

NFES was better absorbed by primates of the 2-experimental group by $7.99 \%$. In the primates of the 3-experimental group, the coefficient of digestibility was higher by $2.78 \%$ than in the control group.

Good indicators for the assimilation of raw ash were noted in the experimental groups. As indicated by the data in Table 2, the digestibility coefficients were higher than in the control group, by 4.67 and $11.28 \%$.

The use of calcium (Ca) and phosphorus (P) macronutrients was higher in the experimental groups. In the primates of the 2-experimental group, the digestibility coefficient of calcium (Ca) was higher by $6.99 \%$, and phosphorus (P) - by $1.02 \%$. In the 3-experimental group, calcium was absorbed more efficiently by $9.93 \%$, and phosphorus - by $8.68 \%$.

Thus, the use of white lupine in the structures of complete feeds for M. mulatta, as a substitute for high-protein feeds of plant and animal origin, had a positive effect on the digestibility of nutrients.

It is of scientific interest to study the biochemical parameters of blood, the effect on the physiological state of primates whose diet included white lupin. To assess the effect of the lupin introduction into the diet on the metabolism, we determined some biochemical parameters of blood serum (Table 3).

Table 3. Blood biochemical parameters, $\mathrm{X} \pm \mathrm{Sx}$.

\begin{tabular}{|c|l|l|c|c|c|c|c|}
\hline \multirow{2}{*}{ Indicators } & \multirow{2}{*}{$\begin{array}{l}\text { Reference } \\
\text { values } a^{*}\end{array}$} & \multicolumn{2}{|c|}{ At the beginning of the experiment } & \multicolumn{3}{c|}{ At the end of the experiment } \\
\cline { 3 - 8 } & & 1 -control & $\begin{array}{c}2- \\
\text { experiment }\end{array}$ & $\begin{array}{c}3- \\
\text { experiment }\end{array}$ & 1 -control & $\begin{array}{c}2- \\
\text { experiment }\end{array}$ & $\begin{array}{c}3- \\
\text { experiment }\end{array}$ \\
\hline $\begin{array}{c}\text { Glucose } \\
\text { (mmol/l) }\end{array}$ & $1.83-6.66$ & $6.02 \pm 0.10$ & $3.40 \pm 0.76^{* *}$ & $7.40 \pm 0.01^{* *}$ & $5.72 \pm 0.08$ & $5.30 \pm 0.17^{*}$ & $6.40 \pm 0.03^{*}$ \\
\hline $\begin{array}{c}\text { Bilirubin } \\
\text { (umol/l) }\end{array}$ & $1.71-11.97$ & $7.57 \pm 1.60$ & $8.35 \pm 1.59$ & $8.57 \pm 2.46$ & $5.325 \pm 1.14$ & $5.441 \pm 3.02$ & $3.357 \pm 0.40$ \\
\hline Protein, (g/l) & $39-78$ & $81.58 \pm 3.49$ & $80.73 \pm 4.31$ & $72.57 \pm 9.30$ & $96.51 \pm 6.71$ & $74.73 \pm 3.30$ & $98.59 \pm 3.04$ \\
\hline
\end{tabular}




\begin{tabular}{|l|l|l|l|l|l|l|l|}
\hline $\mathrm{Ca},(\mathrm{mmol} / \mathrm{l})$ & $1.75-2.45$ & $2.35 \pm 0.29$ & $4.11 \pm 0.61$ & $3.79 \pm 0.13^{* *}$ & $2.329 \pm 0.06$ & $2.523 \pm 0.10$ & $2.543 \pm 0.11^{*}$ \\
\hline $\mathrm{P},(\mathrm{mmol} / \mathrm{l})$ & $1.06-2.13$ & $1.75 \pm 0.76$ & $1.53 \pm 0.04$ & $1.46 \pm 0.30$ & $0.4623 \pm 0.07$ & $0.69 \pm 0.06$ & $0.89 \pm 0.23^{*}$ \\
\hline
\end{tabular}

$*$ - $\mathrm{p}<0.05, *-\mathrm{p}<0.01, * *$ compared with the control group. The data is given in the form of an average value and a standard error.

$a^{*}$ - reference data are given according to [24].

At the beginning of the experiment, in the control and 2-experimental groups, the glucose level was within the physiological norm (Table 3), but in the 3 -experimental group, there was an increase in the glucose content by $12 \%$ with statistical significance $(\mathrm{p}<0.01)$. At the end of the experiment, in the 3-experimental group, after the introduction of white lupin into the structure of the diet, the glucose level was in the reference values of the physiological norm with statistical significance $(\mathrm{p}<0.05)$. In the 2 -experimental group, both at the beginning and at the end of the experiment, the glucose level was within the reference values.

At the beginning of the experiment, the level of bilirubin, a bile pigment, was within the reference values. At the end of the experiment, the average value of the bilirubin level in the experimental groups did not change relative to the control group, but the differences did not reach statistical significance $(\mathrm{p}>0.05)$.

The level of blood protein in the animals was higher than the reference values in all groups both at the beginning and at the end of the experiment. At the end of the experiment, the third experimental group showed a higher content of serum protein by $2 \%$ compared to the control group, $p>0.05$. The increased level of serum protein at the beginning of the experiment was probably transient and was not associated with the action of white lupin in the diet of primates.

The level of calcium and phosphorus in the blood of animals of all three groups, at the beginning of the experiment, was within the reference values. In the final stage of the experiment, these indicators in the experimental groups changed in relation to the control group. The level of calcium $(\mathrm{Ca})$ in the blood serum of primates of the 2-experimental group was $8 \%$ higher, in the 3 -experimental group - by $9 \%$ with statistical significance $(p<0.05)$. The level of phosphorus (P) in the 2-experimental group was higher by $50 \%$, in the 3 experimental group - by $93 \%$ with statistical significance $(p<0.05)$ (Table 4$)$, the data obtained are consistent with higher coefficients of phosphorus assimilation in 2 nd and $3 \mathrm{rd}$ groups (Table 2).

Our results on the biological availability of nutrients, consistent with the literature on the improvement of digestibility of nutrients with the introduction of Lupinus albus in the diet of store pigs $[18 ; 22 ; 26 ; 28]$ and the previously received data to increase the digestibility of crude protein, crude fiber and digestibility of calcium (CA) and phosphorus $(\mathrm{P})[3 ; 4 ; 5 ; 19$; $20 ; 21]$.

\section{Conclusion}

Thus, the use of white lupine in the structures of complete feed for M. mulatta, as an alternative source of a high-protein component in the diets of non-human primates, had a positive effect on the bioavailability of nutrients in the diet as a whole. At the same time, the results of hematological tests of M. mulatta indicate the safety of consumption of white lupine for 35 days. The use of white lupin in diets allows to replace some of the animal proteins with Lupinus albus protein and balance the diet with nutrients and biologically active substances. At the same time, it allows to significantly increase the level of metabolism. 


\section{References}

1. A.I. Artyukhov, N.V. Gaponov, Energy-sugar-protein concentrate and its preparation method, Patent for the invention RU 2461211 C2, 20.09.2012. Application No. 2010144896/13 dated 02.11.2010.

2. P.I. Viktorov, V.K. Menkin, Methods and organization of zootechnical experiments, 112 (M.: Agropromizdat, 1991)

3. N.V. Gaponov, Feed production 1, 42-48 (2021)

4. N.V. Gaponov, A method for optimizing complete mixed feed with fish meal to reduce the cost of keeping primates, Patent No. 2733291 dated October 01, 2020. Application No. 2019144389

5. N.V. Gaponov, Collection of scientific works of the Krasnodar Scientific Center for Animal Science and Veterinary Medicine 9(1), 143-148 (2020) doi:10.34617/02f8-d850

6. N.V. Gaponov, Innovations and food security 4(30), 101-107 (2020). doi: 10.31677/2072-6724-2020-30-4-101-107

7. A.P. Kalashnikov [et al.] Norms and rations offeeding of agricultural animals: reference book/. 3 ver. rev. and add., 456 (Moscow, 2003)

8. A.I. Ovsyannikov, Fundamentals of experimental business in animal husbandry, 304 (Moscow: Kolos, 1967)

9. O.Yu. Rebrova, Journal of Neurology and Psychiatry 11, 71-74 (2010)

10. V.I. Rutskaya, N.V. Gaponov, Legumes and cereals 1(37), 83-89 (2021). doi: 10.24412/2309-348X-2021-1-83-89

11. DR, Ballester, O, Brunser, MT, Saitua, JI, Egana, EO Yanez, and DF Owen, Nine Month Feeding and Multi-Generation Study in Rats. Food and Chemical Toxicology 22, 45-48 (1984)

12. Barneveld Wang. Understanding the nutritional chemistry of lupine (Lupinus spp) seeds to improve animal husbandry efficiency, Nutrition Research Reviews 12, RJ, 203-230 (2000).

13. K. Benjamin, Encyclopedia of Human Nutrition Reference work - Second edition No. 2005, 270 (Johns Hopkins University, Maryland, USA. 2005)

14. E.U. Duane, E.A. Mary, M.A. Lynne, L.C. Nancy, S.E. Mark, Nutrient Requirements of Nonhuman Primates Second Revised Edition, 2003, AD Hoc committee on nonhuman primate nutrition, Committee on animal nutrition, board on agriculture and natural resources, 286 (The national academies press Washington, D.C., 2003). ISBN 978-0309-06989-2 | doi: 10.17226/9826

15. G. Dunaif and B.O. Schneeman, American Journal of Clinical Nutrition 34, 1034-1035 (1981)

16. J.I. Egana, R. Uauy, X. Cassorla, G. Barrera, and E. Janez, Nutrition Diary 122, 341-347 (1992)

17. B.O. Eggum, G. Tomes, R.M. Beams and F.U. Dutta, Animal Feed Science and Technology 43, 109-119 (1993)

18. J.A. Fernandez, and E.S. Batterham, Scientific and technical channel for animals 53, 279-296 (1995)

19. N.V. Gaponov, T.N. Lenkova, Innovacionnye nauchnye issledovaniya 12 (1(2)), 6-16 (2020) doi: 10.5281/zenodo.4444589 
20. N.V. Gaponov, O.P. Neverova, O.V. Gorelik, and A.V. Stepanov, E3S Web of Conferences, (DAIC 2020), 222, 02006 (2020). doi: 0.1051/e3sconf/202022202006

21. N.V. Gaponov, G.L. Yagovenko, A.N. Stepanova, O.P Neverova, and O.V. Gorelik, E3S Web of Conferences, (DAIC 2020), 222, 02005 (2020) doi: $10.1051 / \mathrm{e} 3$ sconf/202022202005

22. J. Gdala, A.M. Jansman, Leeuwen Van., P.J. Huisman, and M.A. Verstegen, Scientific and technical channel for animals 62, 239-249 (1996)

23. G. Grant, P.M. Dorward, W.C. Buchan, J.C. Armor, and A. Pusztai, British Journal of Nutrition 73, 17-29 (1995)

24. B-S. Koo, D-H. Lee, P. Kang, et al., Lab. Anim. Res. 35(1), 7 (2019). doi: 10.1186/s42826-019-0006-0.

25. F. Mariotti, M.E. Puejo, D.I. Tomas, S. Mahe, Published online by University of Cambridge Press 87(B 4), 315-323 (2007)

26. M.A. Mcniven, and A.G. Castell, Scientific and technical channel for animals 52, 333338 (1995)

27. D.J. Millward, and P.J. Pacy, Clinical Science (Colch) 88, 597-606 (1995)

28. L. Molvig, L.M. Tabe, B.O. Eggum, A.E. Moore, S. Craig, D. Spencer, and T.J. Higgins, Proceedings of the National Academy of Sciences, USA 94, 393-398 (1997)

29. National Research Council (US) Committee for the Update of the Guide for the Care and Use of Laboratory Animals. Guide for the Care and Use of Laboratory Animals. 8th ed. National Academies Press (US); (2011). Accessed May 1, 2019. http://www.ncbi.nlm.nih.gov/books/NBK54050/

30. M.H. Rahman, M.I. Hossein, British Journal of Nutrition 77, 443-457 (1997) 